\title{
FUTURE GENERATION TECHNOLOGY STATUS WITHIN THE HIGH- PERFORMANCE PV PROJECT
}

Martha Symko-Davies, Robert McConnell and Fannie Posey-Eddy

\author{
National Center for Photovoltaics \\ National Renewable Energy Laboratory \\ 2006 IEEE $4^{\text {th }}$ World Conference \\ May 11, 2006
}

NREL/PR-520-39867

Presented at the 2006 IEEE 4th World Conference on Photovoltaic Energy Conversion (WCPEC-4) held May 7-12, 2006 in Waikoloa, Hawaii. 


\section{Disclaimer and Government License}

This work has been authored by Midwest Research Institute (MRI) under Contract No. DE-AC36-99G010337 with the U.S. Department of Energy (the "DOE"). The United States Government (the "Government") retains and the publisher, by accepting the work for publication, acknowledges that the Government retains a non-exclusive, paid-up, irrevocable, worldwide license to publish or reproduce the published form of this work, or allow others to do so, for Government purposes.

Neither MRI, the DOE, the Government, nor any other agency thereof, nor any of their employees, makes any warranty, express or implied, or assumes any liability or responsibility for the accuracy, completeness, or usefulness of any information, apparatus, product, or process disclosed, or represents that its use would not infringe any privately owned rights. Reference herein to any specific commercial product, process, or service by trade name, trademark, manufacturer, or otherwise does not constitute or imply its endorsement, recommendation, or favoring by the Government or any agency thereof. The views and opinions of the authors and/or presenters expressed herein do not necessarily state or reflect those of MRI, the DOE, the Government, or any agency thereof. 


\section{High Performance PV Project Description}

- Explore the ultimate performance limits of PV technologies, doubling sunlight-to-electricity conversion efficiencies, lowering costs

- Bring thin-film tandem cells and modules toward $25 \%$ and $20 \%$ efficiencies, respectively.

- Develop multijunction concentrators able to convert more than onethird of the sun's energy to electricity (i.e., $33 \%$ efficiency)

- Increase baseline efficiency of $3^{\text {rd }}$ generation PV concepts (from $39 \%$ baseline to $50 \%$ ) and increase efficiency of potentially low-cost organic solar cells (from $11 \%$ baseline for the dye cell to $20 \%$ ).

- Enable progress of high efficiency technologies toward commercialprototype products 


\section{Best Research-Cell Efficiencies}

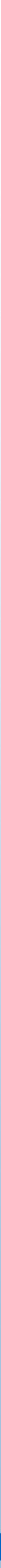




\section{Objectives of Future Generation}

- Increase baseline efficiency of $3^{\text {rd }}$ generation PV concepts (from $39 \%$ baseline to $50 \%$ ) and increase efficiency of potentially lowcost organic solar cells (from $11 \%$ baseline for the dye cell to $20 \%$ ).

- Support the DOE Solar Energy Technologies Program: MultiYear Technical Plan (MYTP)

- Organic Solar Cells

- Initiate theoretical studies for doping organic materials

- Determine operational characteristics of excitonic solar cells using biomimetic, organic, and nanotechnology concepts

- Assess efficiency potential, stability, and reliability of organic polymer and small-molecule solar cells

- Identify commercialization pathways for promising new technologies via university/industrial partnerships

- Dye-sensitized Solar Cells

- Assess efficiency potential, stability, and reliability of inorganic/organic solar cells

- Assess dye-sensitized solar cell options involving solid-state electrolytes. 


\section{Objectives (continued)}

- Support the MYTP

- Nanostructure Solar Cells

- Determine operational characteristics of excitonic solar cells using nanotechnology concepts---including biomimetic concepts mimicking a solar biological process

\section{- Third-Generation Technologies}

- Demonstrate feasibility of third-generation PV devices such as hot-carrier and impact-ionization concepts

- Assess potential of nanotechnologies for achieving thirdgeneration goals of very high efficiency and very low cost. 


\section{- Future Generation--Subcontractors}

- Organic Solar Cells

- Princeton University (Steven Forrest)

- Project Title: Approaching 10\% Conversion Efficiency using Tandem Organic Photovoltaic Cells with Enhanced Optical Coupling

- Collaborator: Global Photonic Energy Corp.

- Northwestern University (Thomas Mason)

- Project Title: Interface and Electrode Engineering for Next-Generation Organic Photovoltaic Cells

- Collaborators: BP Solar, Konarka, Northwestern Departments of Chemistry, Physics and Astronomy, and Materials Science and Engineering.

- Dye-Sensitized Solar Cells

- University of Colorado (Josef Michl)

- Project Title: Ultra High Efficiency Excitonic Solar Cell

- Collaborators: University of Nevada-Reno, University of Wisconsin-Madison, Northwestern University, NREL (Art Nozik).

- Third-Generation Technologies

- University of Delaware (Christiana Honsberg)

- Project Title: Theoretical and Experimental Investigation of Approaches to $>50 \%$ Efficient Solar Cells

- Collaborators: Imperial College, Purdue University, University of New South Wales. 


\section{Summary of Activities}

- Methods and Expected Outcomes--Subcontractors

- Organic Solar Cells

- Princeton University (Stephen Forrest)

- Develop "toolbox" of concepts for optimizing organic solar cells targeting $10 \%$ efficiency

- Northwestern University (Thomas Mason)

- Characterize stability of n-type TCOs for candidate organic solar cells

- Dye-Sensitized Solar Cells

- University of Colorado (Josef Michl)

- Synthesize multiple-exciton generation sensitizer for dye solar cell targeting $20 \%$ efficiency

- Third-Generation Technologies

- University of Delaware (Christiana Honsberg)

- Develop design rules for non-conventional PV conversion processes leading to $>50 \%$ efficient solar cells 


\section{In-house Activities}

- NREL Basic Sciences Center (High Efficiency Concepts PV)

- Third Generation Technologies

- Third Generation PV: Quantum Dot Solar Cells (Art Nozik)

- Dye-Sensitized Solar Cells

- Dye-Sensitized Solar Cell Research (Art Frank)

- Computational Modeling, Analysis and Design of PV Materials

- TCO, III-V, Polycrystalline thin films and Si (Suhuai Wei)

- Solid State Spectroscopy of PV Materials

- Enhance designs for high efficiency monolithic multi-bandgap tandem solar cells. Modulated Reflectance (MR) measurements, and Raman measurements(Angelo Mascarenhas)

- Solid State Theory of PV Materials and Devices

- Polycrystalline thin films, new materials for wide-bandgap thin-film top cells, enhance efficiencies of III-V tandem cells for high performance by inserting in them particles creating Intermediate Gap absorption (Alex Zunger) 


\section{Exciton Solar Cells}

- Electrons and holes are still created simultaneously

Dye Solar Cell

- But they are bound together and move as bound pairs to the nearest material boundary

- Separation of electrons and holes at a material interface is followed by diffusion or electrochemical drivers of the charge carriers

- Primarily associated with organic materials...... plastics

-Potentially low costs for materials and processing

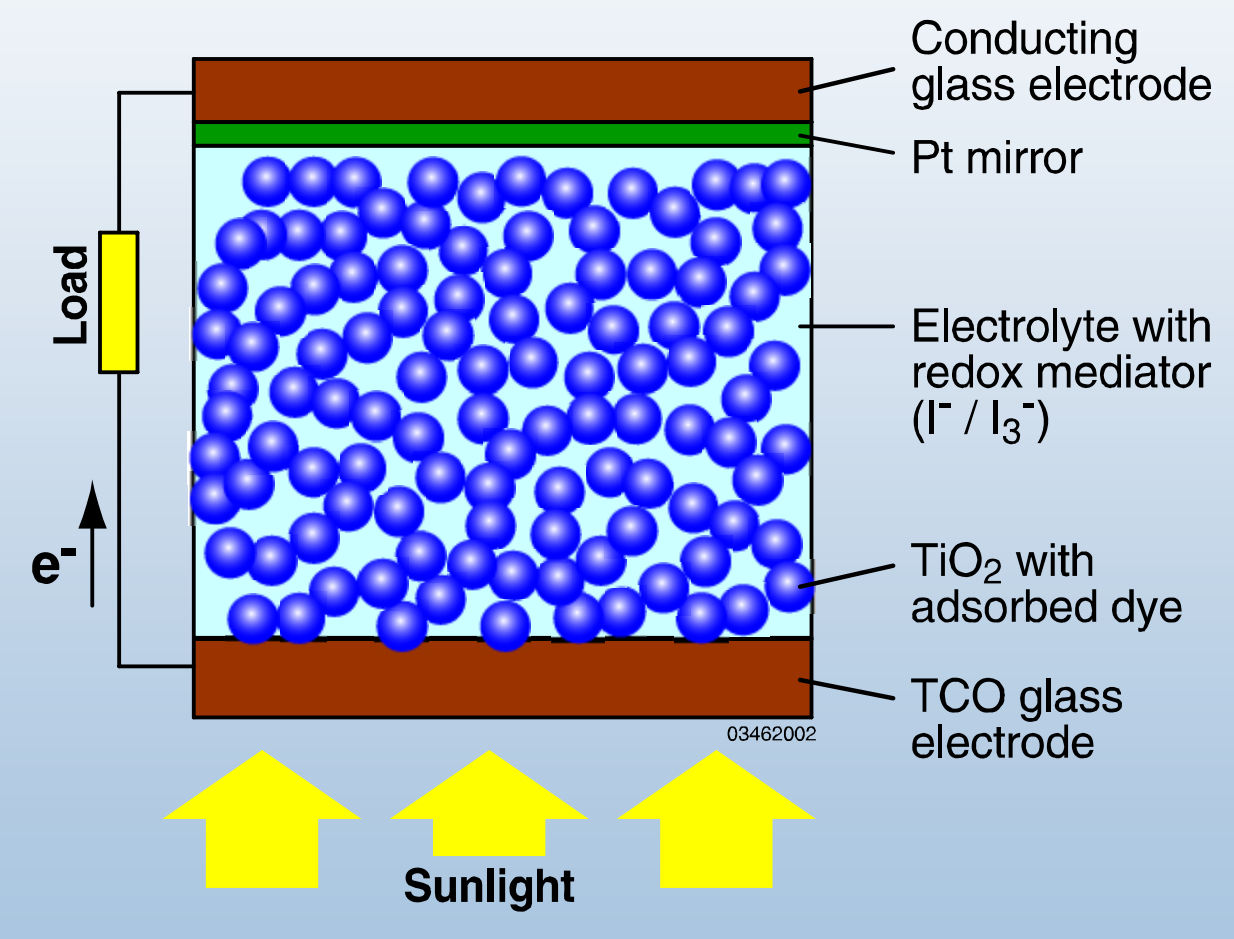




\section{Multiple Electron-Hole Pairs-per-Photon Solar Cells}

- Electron and hole created simultaneously

- Hot electron and hole create multiple (m) electron-hole pairs through Auger emission and absorption instead of thermalizing

- Need materials (e.g., quantum dots) susceptible to creation of multiple Auger electron-hole pairs

- Recently observed by NREL and Los Alamos scientists...3 carriers for 1 photon

- Can be added to a multijunction solar cell stack to achieve higher efficiency

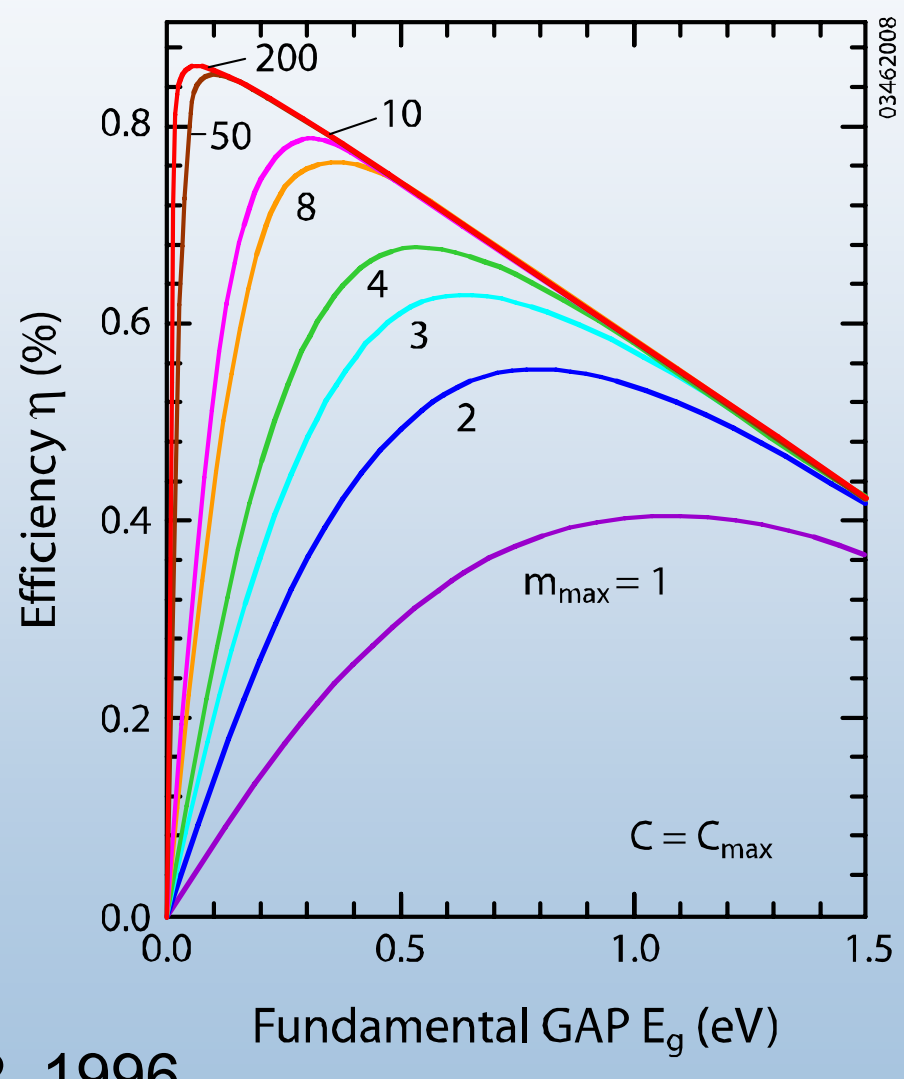

H. Queisser et al., Max Planck Inst., Solar Energy Materials and Solar Cells, 41/42, 1996 


\section{Intermediate-Band Solar Cells}

- Involves a narrow energy level, instead of stacks of energy bands as in multijunction cells

- Theoretical efficiency advantages over equivalent multijunction cells

- Can simplify and augment multijunction solar cell efficiencies

A. Luque et al., U. Politecnica de Madrid Phys. Rev. Lett., 78, No. 26, 1997

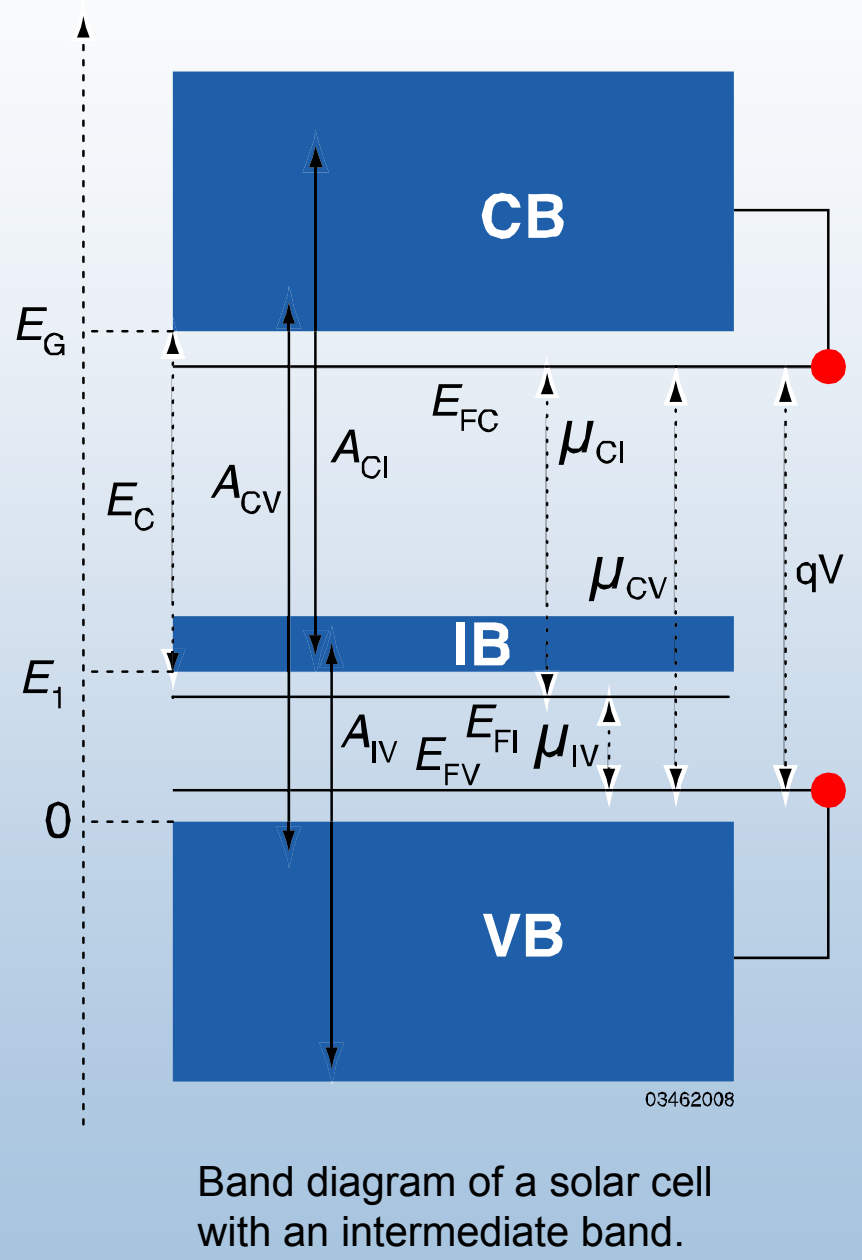




\section{PI: Stephen Forrest, Princeton University}

\section{- Research Objectives:}

Demo organic PV cells with high efficiency by using new structures based on vapor deposited small molecular weight organic thin films.

\section{- Approach:}

1. Demonstrate new materials systems and structures to enhance efficiency.

- $\mathrm{CuPc} / \mathrm{C60}$ demonstrated

- Double heterstructure cell invented

2. Use tandem structures with metal nanoparticles for plasmon optical field enhancements

\section{- Industry Impact:}

Currently working with Global Photonic Energy Corp. to find partners for production and commercialization of our $5+\%$ efficiency cells on low cost plastic (flexible) substrates.

\section{- Significant Results:}

- In a hybrid cell consisting of the organics CuPc/C60 (material system first demonstrated in this program), record efficiencies of $5.9 \%$ under 1 sun, AM1.5 illumination observed.

- First demonstration of organic bulk heterojunction based on small molecular weight materials

- Formation of a bulk heterojunction by thermal annealing of small molecules:

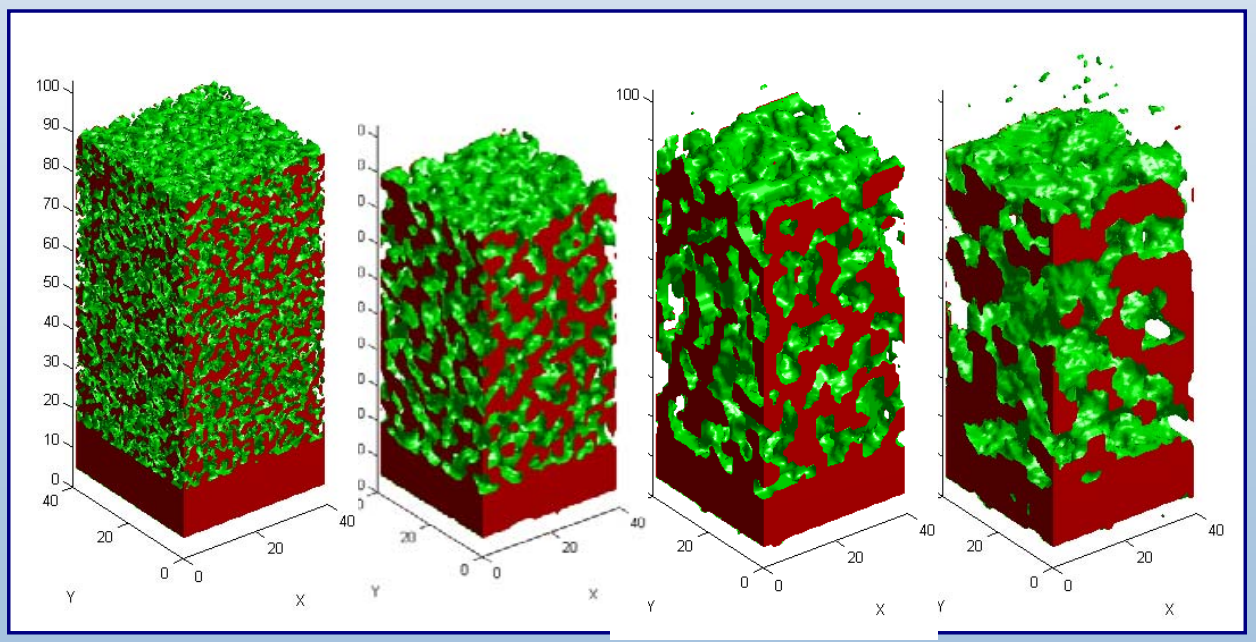

Peumans, et al., Nature 425, 158 (2003) 


\section{Controlled Growth of a Bulk Heterojunction}

\section{Ideal Bulk HJ PV Cell}
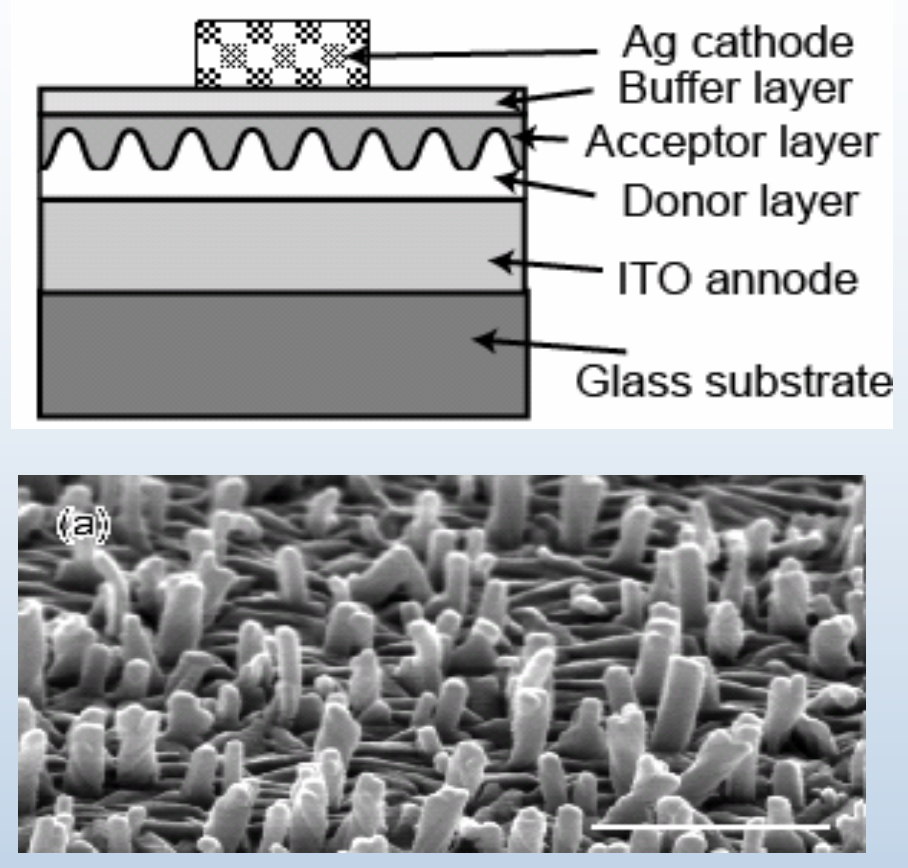

Donor Layer: Highly Folded

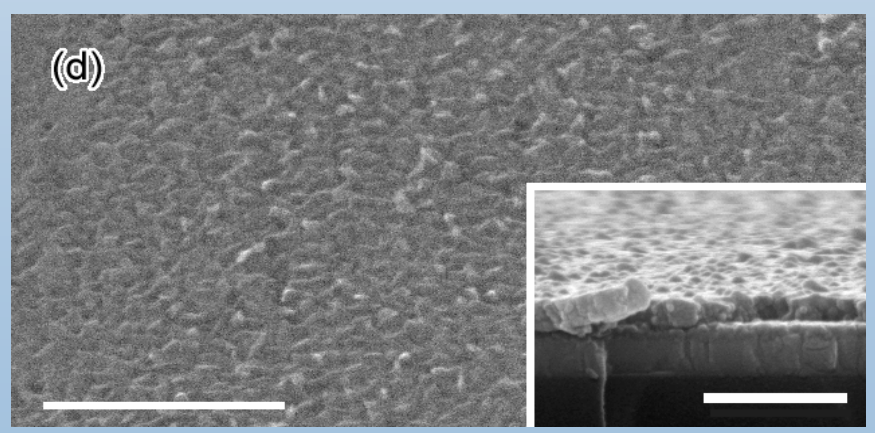

Acceptor Layer: Planarizes Cell

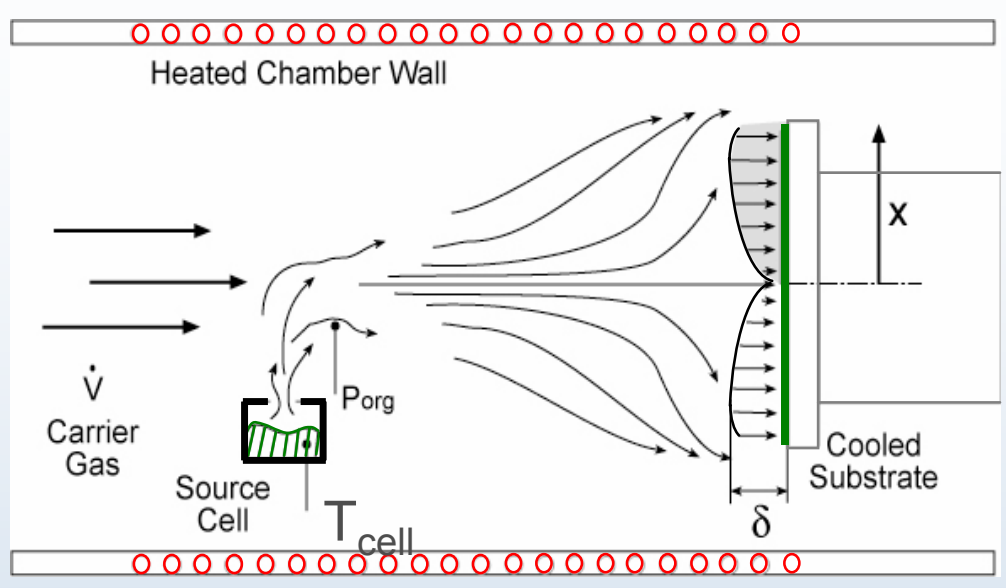

Organic Vapor Phase Deposition: Different strain and growth conditions

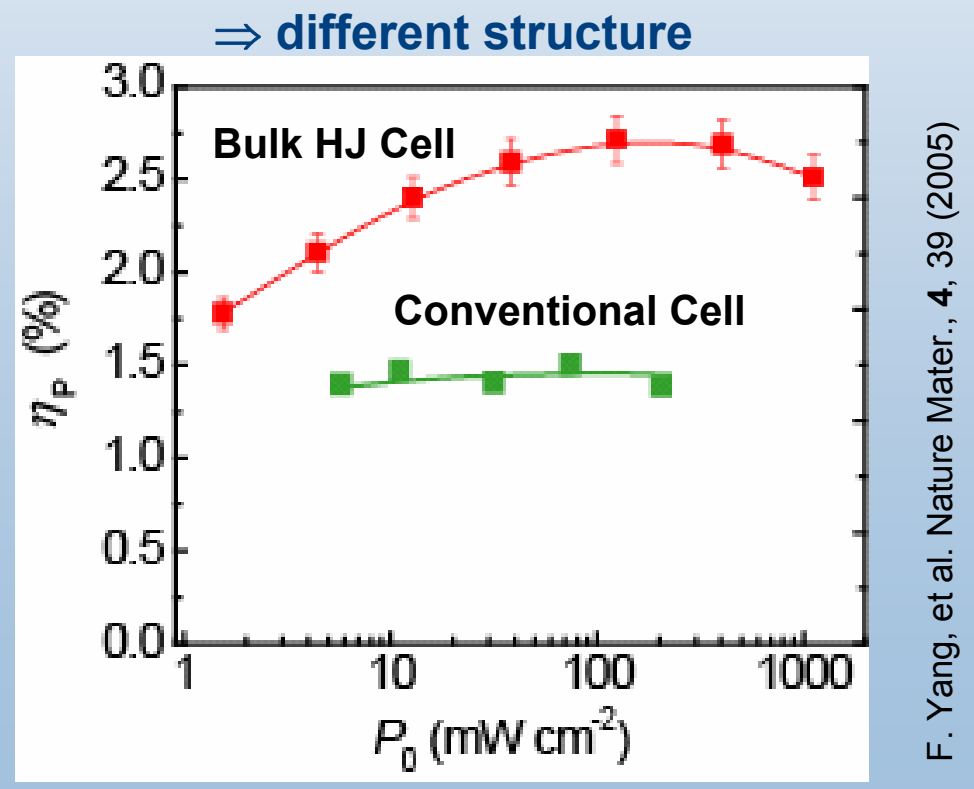




\section{Some Significant Issues Addressed}

$\sqrt{ } \cdot$ Scalability

- Cells thin to maximize absorption and minimize resistance/exciton bottleneck limits $\Rightarrow$ small area to avoid shorts

- ITO very resistive

- Low $\mathrm{V}_{\text {oc }} \Rightarrow$ new materials \& concepts

- Organics typically do not absorb into the IR

- Reliability $\Rightarrow$ packaging, new materials

- Large area, low cost manufacturing

- Plastic substrates

- OVPD 


\section{PI: Thomas O. Mason, Northwestern University}

\section{- Research Objectives:}

To advance the science and technology of next-generation, efficient, easily manufacturable, and durable organic photovoltaics.

\section{- Approach:}

1. Improved transparent electrodes (transparent conducting oxides, TCOs) for efficient organic photovoltaics

2. Engineered organic-transparent electrode interfaces for high-efficiency organic photovoltaics

\section{- Industry Impact:}

Demonstration of prototype OPVs and technology transfer of novel transparent electrodes and engineered organic-TCO interfaces to NREL and our partners (BP Solar, Konarka Technologies)
- Significant Results:

- Interfacial science of OLEDs applicable to OPVs

- Theory-guided synthesis of novel TCOs

- Correlation of surface vs. bulk TCO defect/electronic properties

- Nanostructured TCO electrode materials

\section{Proposed Organic Photovoltaic of the} Future

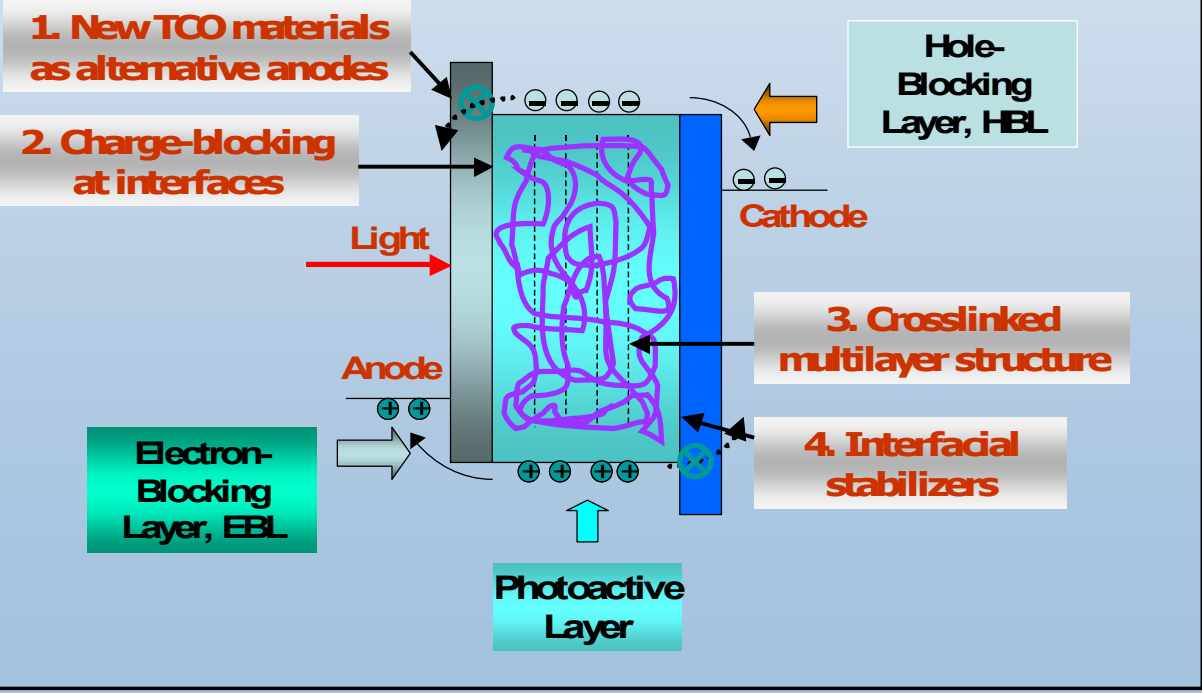




\section{PI: Josef Michl, CU Boulder}

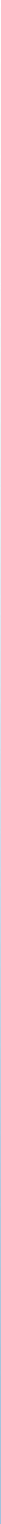




\section{PI: Arthur J. Nozik, NREL}

(Collaborative Project with Office of Science/BES/Chemical Sciences)

\section{- Research Objective:}

To demonstrate multiple electron-hole pair (exciton) generation from single photons in quantum dots (QDs) and apply this effect to QD solar cells to produce greatly enhanced photocurrent and conversion efficiency

\section{-Approach:}

- Synthesize QDs that are expected to show greatly enhanced multiple exciton generation (MEG).

- Measure MEG using transient absorption spectroscopy.

- Develop and characterize nanocrystalline solar cells sensitized with QDs exhibiting efficient MEG and greater photocurrent.

- Model performance of QD solar cells showing efficient MEG.

\section{- Industry Impact:}

Ultra-high conversion efficiency in $3^{\text {rd }}$-generation solar cells could significantly reduce the cost of PV power. Incorporating quantum dot solar cells into multijunction cells already in production could provide a feasible route to $50 \%$ efficient solar cells.
- Significant Results:

1. Quantum yields of up to $300 \%$ (3 electron-hole pairs per photon) were measured in $\mathrm{PbSe}$ and $\mathrm{PbS}$ quantum dots at photon energies 4 times the QD bandgap.

2. The enhanced performance and increased efficiency of QD solar cells based on MEG have been calculated.

- Graphics:

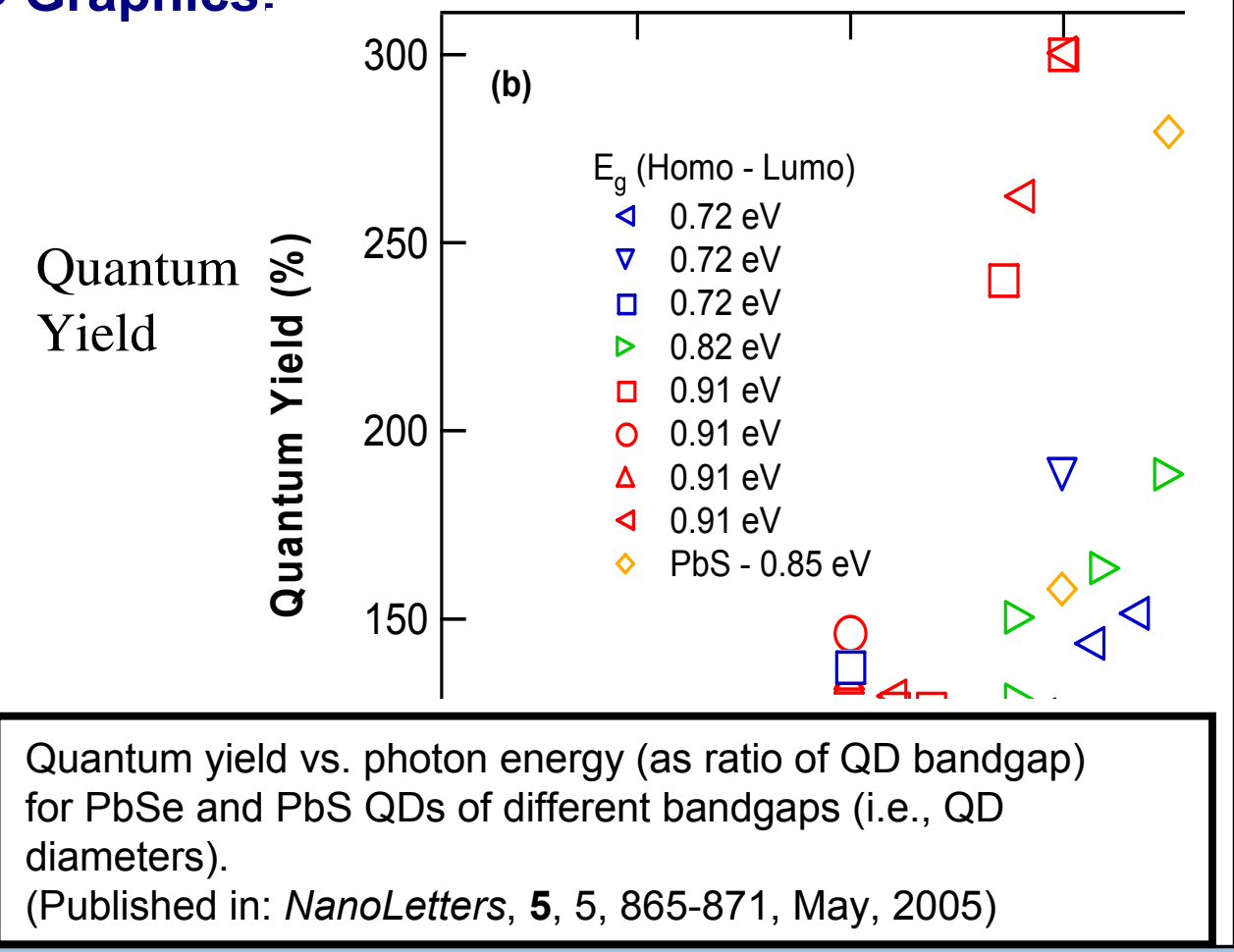




\section{PI: Christiana Honsberg, University of Delaware}

Project Objectives: Develop realistic solar cell device designs capable of reaching an efficiency of $50 \%$

\section{Approach:}

- Analyze physical concepts that increase efficiency above singlejunction device

- Multiple energy level solar cells achieve this and may be implemented with wide range of materials

- Develop practical models for quantum dot multiple energy level solar cells:

1. Program to calculate band structure based on upon energy levels derived from Schrödinger Equation. Searches space of III-V alloys for material that synthesize an optimum band structure.

2. Program to determine optimum band structure taking into account non-idealities including:

- Concentration

- Finite intermediate band width

- Spectral selectivity

- Intraband transitions within the intermediate band

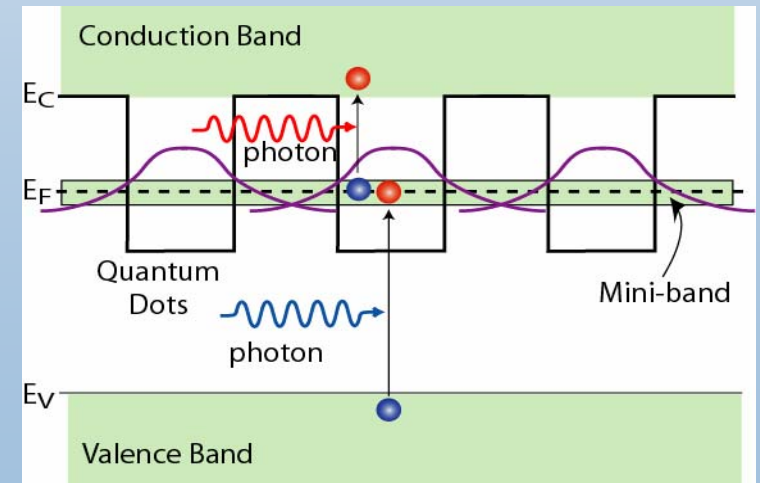

NPE National Renewable Energy Laboratory 


\section{Future Directions}

1. Calculate and include in efficiency calculations the impact of a finite density of states on QD MEL solar cells on radiative transitions (absorption and recombination)

- Calculations based on piece-wise continuous parabolic density of states (DOS).

2. Refine band structure model as needed to include additional effects (e.g. strain) and determine optimum materials including finite DOS calculations.

3. Experimentally implement QD MEL

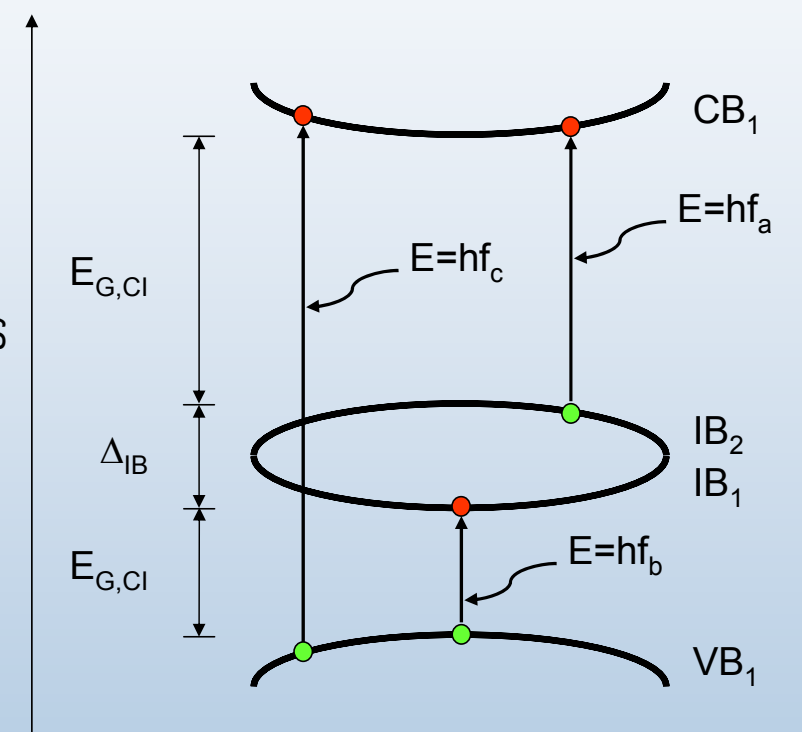
solar cells with optimum materials and demonstrate validity of model and design. 


\section{The Promise of Future Generation PV Remains}

- Theoretical efficiencies are much higher than demonstrated efficiencies.

- New PV materials and devices may be cheaper and more plentiful.

- An English tradition says that if you follow a rainbow to its end, you will find a pot of gold. But to find gold, you have to be patient, supportive of a variety of approaches and capable of affording risk.

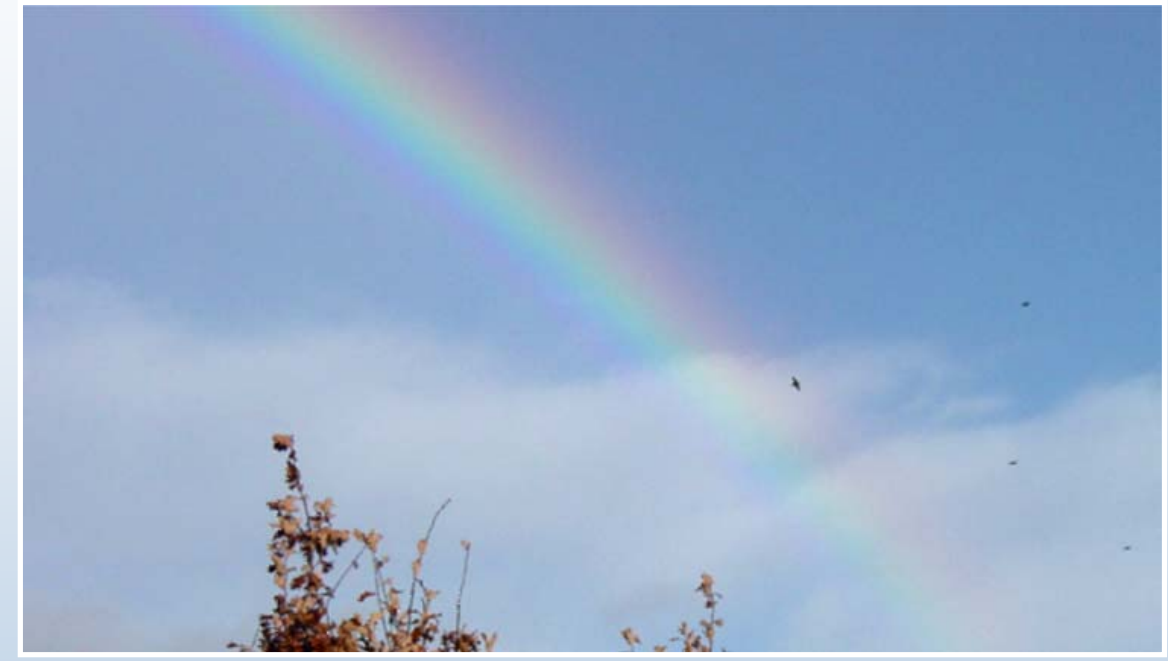

- A cautionary note comes from the ancient Greek writer Sophocles who said: "Look and you will find it — what is unsought will go undetected." 